\title{
Black Egyptian inks in Late Antiquity: new insights on their manufacture and use
}

\author{
Tea Ghigo ${ }^{1,2,3}$ • Ira Rabin ${ }^{2,3} \cdot$ Paola Buzi ${ }^{1,2}$
}

Received: 24 September 2019 / Accepted: 21 November 2019 / Published online: 11 February 2020

(C) The Author(s) 2020

\begin{abstract}
We present here our methodological approach applied to the study of Egyptian inks in Late Antiquity. It is based on an interdisciplinary strategy, bringing together a variety of disciplines from humanities and natural sciences, and it aims at systematically collecting a statistically relevant amount of data regarding the composition of the inks. The application of a wellestablished, non-invasive protocol that includes near-infrared imaging and X-ray fluorescence spectroscopy for in situ measurements enables the identification and characterisation of inks dating from the end of Late Antiquity onwards. However, sometimes this method limits our understanding when characterising more ancient inks. Trying to overcome these limitations, the potential of a new device for the characterisation of organic compounds is here explored by conducting preliminary tests on mock samples. In this work, we present the results from 77 codicological units that include some of the earliest manuscripts of our corpus that presently lists 159 units.
\end{abstract}

Keywords Ink $\cdot$ Manuscript $\cdot$ Multi-instrumental analysis $\cdot$ Papyrus $\cdot$ Interdisciplinary approach

\section{Introduction}

To date, most of the scientific studies focusing on black writing media deal with iron-gall inks and their corrosion patterns (Rouchon-Quillet et al., 2004; Kolar and Strlic 2006; Rouchon and Bernard 2015), while only a minor part of the ongoing research aims at the characterisation of the materials used in the making of historical inks. Among the latter studies, many deal with the characterisation of inks on manuscripts from the Middle Ages onwards (Hahn et al. 2004; Rabin et al. 2014; Aceto and

Tea Ghigo

tea.ghigo@uniroma1.it

Ira Rabin

ira.rabin@bam.de

Paola Buzi

paola.buzi@uniroma1.it

1 ERC advanced grant PAThs, La Sapienza University, Rome, Italy

2 University of Hamburg, Hamburg, Germany

3 BAM (Bundesanstalt für Materialforschung und -prüfung), Berlin, Germany
Calà 2017; Díaz Hidalgo et al. 2018). Similarly, it is well documented that in Antiquity mostly carbon ink was used as a writing material (Lucas 1922; Nicholson and Shaw 2000, pp. 238-239). In contrast, we have very scarce data regarding the manufacturing of inks from the Hellenistic period to the Middle Ages. ${ }^{1}$

Published in 1983, the study on the history of inks by Monique Zerdoun Bat-Yehuda (Zerdoun Bat-Yehuda 1983) is until today the only investigation systematically addressing the technological evolution of inks from Late Antiquity to early Renaissance, in a geographical frame extending from the Mediterranean world to Asia. In her survey, Zerdoun collects the written recipes available in literature, making an effort to identify all their ingredients, despite the terminological difficulties posed by different languages and historical

\footnotetext{
${ }^{1}$ It should be stressed that the definition of different historic periods is a nontrivial issue. Given the different schools of thought regarding the division into periods that exist for ancient history, it is difficult to generalise, and every generalisation leads inevitably to a simplification of the reality. Intending to use such simplification for mere classification purposes, the authors would like to clarify how they interpret the subdivision of historical periods. The time span from the death of Alexander the Great (323 BCE) to the battle of Actium (31 BCE) is referred to as Hellenistic period. It follows the Roman period which ran until the fourth century $\mathrm{CE}$, when the Late Antiquity started. The Middle Ages began in the seventh century CE when the Arabs conquered Egypt.
} 
periods. A parallel systematic approach covering the passage between the Hellenistic period and Middle Ages has never been attempted in the material characterisation of writing inks. The difficulties in getting access to cultural heritage collections, together with the challenges in dealing with manuscripts securely dated, have often discouraged scientists.

This does not mean, however, that no information is available. Scientific literature provides us with some results on the composition of inks from this transition period. The use of pure carbon ink seems to have changed from the Hellenistic period onwards, according to a few analyses that uncovered the presence of metals in carbonbased inks of this period. In the Middle East, we have evidence of copper containing carbon inks in the Genesis Apocryphon scroll from the Dead Sea Scrolls collection (Jerusalem, Shrine of the Book, 1QGenAp) (Nir-El and Broshi 1996), in two fragments of private letters from Pathyris, the nowadays Gebelein, and in two others from the Tebtunis temple library (Copenhagen, Carlsberg collection) (Christiansen et al. 2017). All of them are dating from a period between the last centuries before the Common Era and the first centuries after. Similarly, lead was recently found as an additive in carbon inks on a charred fragment from Herculaneum (Paris, Institut de France) (Brun et al. 2016). Unfortunately, we do not know in what chemical species these metals were added to the ink, given that their presence was detected using X-ray-based techniques. Carbon ink with or without the addition of metals was not the only writing medium in use during the Hellenistic period in Egypt. In a group of bilingual documents preserved at the Louvre and dating between the third and the first centuries BCE (Paris, Musée du Louvre, $N$ 2433, $N$ 2416, $N$ 2410, $N$ 2422), all Demotic texts were written in carbon ink, while Greek texts were penned in a copper-based ink. Although never empirically verified, the presence of tannins in these copper-based inks was tacitly assumed based on their brownish colour (Delange et al. 1990). Finally, among the earliest evidence of iron-gall inks, we can list the Book of Proverbs in Akhmimic preserved at the Staatsbibliothek in Berlin (Berlin, Ms.or.oct 987) dated to the third-fourth centuries CE (Ghigo et al. 2018), the Vercelli Gospel (Codex Eusebii Evangeliorum) at the Museo del Tesoro del Duomo in Vercelli dating probably to the fourth century CE (Aceto et al. 2008), and the Vienna Dioskurides (Vienna, Codex Vindobonensis Med. gr. 1) from the sixth century CE (Aceto et al. 2012).

In an effort to collect more data and fill the gaps of this fragmented scenario, the BAM (Bundesanstalt für Materialforschung und - prüfung) together with the CSMC (Centre for the Study of Manuscripts Cultures, University of Hamburg) created a new project in the framework of their ongoing research on the socio-geographic history of inks.
This work is carried out in a close cooperation with the ERC Advanced Grant 'PAThs" ${ }^{2}$ dedicated to the study of Coptic literature. ${ }^{3}$ Coptic manuscripts were initially chosen as a focus for our investigation because of their continuous production between the Late Antiquity and the Middle Ages. In this context, the project 'PAThs' helps in placing the data obtained from archaeometric analysis in the historical context to which they belong. Based on an interdisciplinary approach involving philology, codicology, archaeology and digital humanities, the 'PAThs' project joins efforts to investigate the processes of production, dissemination and storage of Coptic literary works in relation to their geographical contexts. Its aim is to provide a range of digital tools where the scattered pieces of relevant information available are studied, collected and geochronologically organised to make them accessible to the professionals working in manuscripts cultures (Buzi 2017). Unfortunately, however, Coptic literary manuscripts rarely contain clear information regarding their chronology or geography. Therefore, dating and locating are only possible through a complex analysis that cross-links data regarding the text, the palaeographical and codicological features and the archaeological context of the finding. Given the necessity of collecting data from securely dated and localised manuscripts, we decided to extend our investigation to documentary texts. These are more likely to display a clear indication of the place and date of issuing and can be written in Latin, Greek or Coptic since Egypt was characterised by a multilingual society during Late Antiquity (Bausi 2018; Buzi 2018a). Despite the linguistic bias, the documents investigated were produced in the same areas and similar time span as the Coptic literary texts and represent interesting terms of comparison.

\section{Types of ink and ingredients}

Generally speaking, an ink is a writing medium obtained by mixing a binding agent such as gum Arabic or animal glue with a pigment or a dye. Carbon ink is based on a dispersion of carbon particles in the form of charcoal or soot in the watersoluble binding agent. Plant ink is a solution of tannins derived from tree bark, gallnuts or other vegetal matter containing tannins. Iron-gall ink presents a specific case since the insoluble pigment results from a chemical reaction. The black complex, on which this type of ink is based, is uniquely produced by mixing $\mathrm{Fe}^{2+}$ (obtained, for example from green

\footnotetext{
${ }^{2}$ This article is a scientific outcome of the ERC Advanced Grant (2015) 'PAThs-Tracking Papyrus and Parchment Paths: An Archaeological Atlas of Coptic Literature. Literary Texts in their Geographical Context. Production, Copying, Usage, Dissemination and Storage', directed by Paola Buzi and hosted by Sapienza University of Rome (grant no. 687567) [http:// paths.uniroma1.it/].

${ }^{3}$ The results of Egyptian literary production from the third century CE onwards.
} 
vitriol- $\mathrm{FeSO}_{4} \cdot 7 \mathrm{H}_{2} \mathrm{O}$ ) with gallic acid contained in tannins, which becomes insoluble upon oxidation in air. In contrast to the recipes just described, containing only the basic ingredients required to prepare an ink, written historical sources usually mention a broader variety of constituents, some of which are still not univocally identified. This is the case for chalcanthon ( $\chi \dot{\alpha} \lambda \kappa \alpha \nu \theta o \nu)$, a copper-based substance (in Greek chalcos $=$ copper) whose exact chemical formula in Antiquity evades identification (Bailey 1932, p. 175), though from the Middle Ages onwards, it is clearly identified as copper sulphate (blue vitriol). The term chalcanthon appears in the treatise written in the third century BCE by Philo of Byzantium who uses it to make re-appear invisible text written on leather using gallnut extract (Garlan 1974, p. 324). Around the first century CE, Dioscorides adds this substance to pure carbon ink, mentioning its good antiseptic properties (Dioscorides Pedanius et al. 2000, book V: 114, 183). The same chalcanthon appears in the Papyrus V of Leiden dating to the third century CE (Preisendanz 1931, p. 83), where it is mixed with gum, gallnut extract, myrrh and misy (allegedly, a metallic salt whose composition has never been clarified) to prepare a magical ink (was it iron-gall?). Pliny wrongly equates this substance with atramentum sutorium (Rabin 2017) and aware of his mistake recent literature often refers to it as a mixture of copper, iron and other sulphates, commonly called vitriol (Zerdoun Bat-Yehuda 1983; Karpenko and Norris 2002). To date, there is no evidence that allows to disambiguate the chemical composition of this substance before the Middle Ages.

\section{Corpus of investigation and institutions involved}

For the time being, our investigation includes 159 different codicological units (i.e. one or more fragments preserved in a certain place and belonging to the same original manuscript). They include manuscripts on papyrus, parchment, paper and ostraca which were distributed across a very broad time span (third century $\mathrm{BCE}$-eleventh century $\mathrm{CE}$ ) and which were produced in different areas of Egypt. The fragments are nowadays preserved in the collections of eigth different institutions: the Museo Egizio in Turin, the Biblioteca Apostolica Vaticana in Rome, the Staatsbibliothek and the Ägyptisches Museum und Papyrussammlung in Berlin, the Cambridge University Library, the Chester Beatty Library in Dublin, the Fundació de San Lucas Evangelista in Barcelona and the Monasterio de Santa Maria in Montserrat. The fragments studied were chosen based upon several criteria. The conservation state is of course a limiting factor when handling fragile materials, and therefore the first criterion in discriminating the selection. Despite this limitation, we strived to choose manuscripts coming from renowned scriptoria or archaeological findings, giving priority to those whose dating and production place were more securely assessed.

In this work, we present the results obtained on some of the earliest manuscripts we studied, dated to the period between the second and eighth centuries CE. They are divided into three clusters according to their date, provenance and text genre. Here, we discuss the correspondence between these variables and the type of ink. Although only a limited number of leaves are illustrated in this article as being representative of a cluster, the contribution of this work lies in the attempt at examining a relevant number of manuscripts to draw conclusions on the distribution of the ink typology throughout space and time. Table 1 lists the shelf marks of the manuscripts presented, the details regarding their dating, language and provenance and the cluster to which each manuscript belongs, along with the total number of units forming part of such cluster.

The first cluster of manuscripts forms part of the collection from the Cathedral of Thi(ni)s, nowadays Ğirğā, and is preserved at the Museo Egizio in Turin. The library of Thi(ni)s is indeed a crucial and transitional instance in the history of Coptic manuscripts, which saw on the one hand the creation of new codicological and palaeographical features and on the other hand the progressive emergence of multiple-text codices (Buzi 2017; Buzi 2018b). Additionally, the fact that the manuscripts in question have very likely been manufactured in a limited span of time and have been penned by a limited number of copyists, placed the study of the library of Thi(ni)s as a first choice in our corpus.

The manuscripts of the second cluster have in common the dating, palaeographically established around the fourth century CE. Of these 3 codicological units, the Apostolic Vatican Library, Pap. copt. 9 and the Montserrat, Roca Puig, Inv. 145 are probably part of the so-called Bodmer Library, one of the most famous collections of papyri from Late Antique Egypt (Fournet 2015). It owes its name to a rich collector from Switzerland, Martin Bodmer, who in the 1950s exported an important batch of manuscripts from Egypt. The collection acquired by Bodmer was then dismembered in the following years, often by Bodmer himself, as it is the case of the leaves he donated to Pope Paul VI, now preserved in the Apostolic Vatican Library. From 1960 onwards, Bodmer stopped the importation of papyri, but Ramón Roca Puig still acquired some leaves, probably coming from the same findings, that are nowadays preserved in the Monasterio de Santa María in Montserrat (Schubert 2015). The exact composition, dating and provenance of this collection are still debated. One of the hypotheses indicates that the manuscripts were produced around the fourth century CE in the Pachomian Monastery of Pbou, close to the area of Panopolis, where they were probably found (Fournet 2015; Lundhaug and Jenott 2015).

The third codicological unit belonging to this cluster is known as Athanasius' roll (Montserrat, Roca Puig collection, Inv. 14) and is not considered to be part of the Bodmer 
collection. The dialect used in the roll indicates that it was produced in the area around Panopolis (Torallas Tovar 2018). This means that if the hypothesis regarding the Bodmer collection is accepted, all the manuscripts from cluster 2 have in common not only the dating but also the provenance. Finally, the results obtained on the literary manuscripts from these two clusters will be compared with those obtained on the third cluster, formed by documentary texts produced in various areas of Egypt between the second and eighth centuries $\mathrm{CE}$.

\section{Experimental}

Our standard protocol for ink analysis consists of a primary screening to determine the type of ink and a subsequent indepth analysis using several spectroscopic techniques: XRF and, only occasionally, FTIR and Raman (Rabin et al. 2012).

The primary screening is carried out by means of nearinfrared reflectography. Strictly speaking, optical differences between carbon, plant and iron-gall inks are best recognised when comparing their response to the infrared light: carbon ink has a deep black colour, iron-gall ink becomes transparent above $1400 \mathrm{~nm}$ and plant ink disappears at ca. $750 \mathrm{~nm}$ (Mrusek et al. 1995). ${ }^{4}$ The in-depth investigation includes $\mathrm{XRF}$ analysis to obtain the contribution of the inorganic components of the ink. In the case of iron-gall inks, we establish the fingerprints, i.e. the characteristic ratios of the metallic components of the ink (Hahn et al. 2004; Rabin et al. 2012).

This non-invasive and portable analytical protocol has proved to be very effective in characterising inks based on late Medieval European recipes, offering great support to the codicological analysis (Hahn et al. 2007; Rabin et al. 2014; Geissbühler et al. 2018; Hahn et al. 2018). However, it does not contain a routine identification of the organic components, and therefore, it does not offer full elucidation and becomes problematic when unknown media such as Late Antique inks are under scrutiny. In a previous work, we extensively pointed out the difficulty in characterising mixed inks using our current protocol (Colini et al. 2018). Given the inability of detecting tannins, we cannot distinguish carbon inks containing metals from mixtures of carbon and iron-gall inks. For the same reason, we cannot identify mixtures of carbon and plant ink. In order to achieve a more accurate characterisation, we decided to test the potential of mass spectrometry, thanks to a new portable sample holder that allows to collect a negligible amount of sample. If successful, this technique would allow to gain insights into the nature of binders and tannins employed in the making of the ink. Although extensively mentioned in

\footnotetext{
${ }^{4}$ In their study, Mrusek et al. indicate that iron-gall ink becomes transparent at $1200 \mathrm{~nm}$. However, our recent tests using an IR camera showed that fresh irongall ink becomes completely transparent at longer wavelengths.
} 
medieval recipes, gallnuts are not the only source of tannins historically used in the ink making. Theophilus, for example mentions the use of the bark from a bush (Theophilus 1979, p. 49), and analytical evidence coming from some Yemenite fragments dating between the seventh and eighth centuries $\mathrm{CE}$ suggests the use of other ingredients than gallnuts (Bicchieri et al. 2013). Therefore, the discrimination between different families of tannins, namely hydrolysable (highly concentrated in gallnuts) and condensed (present in mangrove), may offer a valuable parameter for the classification of inks. In this work, we present for the first time the results obtained from a laboratory study on a set of mock samples.

\section{DinoLite USB microscope, AD413T-I2V}

This small USB microscope measures only $10 \mathrm{~cm}$ and it is equipped with three different lights sources: near-infrared (940 nm), UV (395 nm) and a white LED light (external). Comparing the VIS micrograph with the corresponding near-infrared, we determine the ink typology by observing the changes in the opacity of the ink. At $940 \mathrm{~nm}$, carbonbased inks show no change in their opacity, while the opacity of iron-gall inks changes considerably, and plant inks become transparent.

\section{Elio Bruker Nano GmbH (formerly XG Lab)}

This X-ray spectrometer features a 4-W low-power rhodium tube, adjustable excitation parameters and a $17-\mathrm{mm}^{2}$ SDD detector with energy resolution $<140 \mathrm{eV}$ for $\mathrm{Mn} \mathrm{K} \alpha$. It was used to collect measurement on single spots and has a beam size of ca. $1 \mathrm{~mm}$. All measurements were performed at $40 \mathrm{kV}$ and $80 \mu \mathrm{A}$, with an acquisition time of $2 \mathrm{~min}$. Peak fitting and semi-quantitative data evaluation were conducted using Bruker's SPEKTRA software.

\section{ArtTAX 800 Bruker Nano GmbH}

ArtTAX is an X-ray spectrometer well known in the field of cultural heritage and belongs to the standard equipment in the majority of large museums. It features a low-power, air-cooled molybdenum X-ray tube, polycapillary optics resulting in a beam spot of about $100-\mu \mathrm{m}$ diameter, a CCD camera for sample positioning and an electrothermally cooled Xflash detector (SDD, area $10 \mathrm{~mm}^{2}$ ) with an energy resolution of $<150 \mathrm{eV}$ for $\mathrm{Mn} \mathrm{K} \alpha$ at $10 \mathrm{kcps}$. The movable probe is operated by XYZ motors that enable spot measurements to be performed as well as line and small area scans. The mobile XRF probe moves over the object at ca. 5-mm distance and stops for the duration of a single measurement. All measurements were made along a line containing between 10 and 30 spots for analysis, operating at $50 \mathrm{kV}$ and $600 \mu \mathrm{A}$, with an acquisition time of $30 \mathrm{~s}$ per spot (live time). Peak fitting and semi-quantitative data evaluation were conducted using Bruker's SPEKTRA software.

\section{ASAP Xevo G2-XS QTOF Waters}

This is a useful tool for the analysis of volatile and semivolatile solid and liquid samples using atmospheric pressure ionisation (API). This technique utilises a heated nitrogen desolvation gas to vaporise the sample and a corona discharge for sample ionisation. Complex mixtures can be analysed without the need of any sample preparation. The sample is simply collected by rubbing the glass sampler on solid analytes or by immersing it in liquid analytes. Then, it is inserted in the instrument for examination. The analysis was performed using negative-ion pattern, with de-solvation temperature of $650{ }^{\circ} \mathrm{C}$ and corona current of $10 \mu \mathrm{A}$. The mass range considered was between 50 and $1200 \mathrm{Da}$ with a scan time of $1 \mathrm{~s}$.

\section{Results and discussion}

When investigating iron-gall inks, the fingerprint model has been suggested in the past as a possible approach to perform qualitative and quantitative studies of ink traces on paper writing surfaces (Hahn et al. 2004). We often successfully apply a simplified version of this model that considers only an approximation of the contribution from the support and yet gives an indication of the different writing phases involved in the production of a manuscript. The model involves at first the subtraction of the net peak intensity of all the elements in the support from the values of the corresponding elements in the inked areas. This is a necessary step given that the X-rays are penetrating and measuring the contribution from the support and ink together. The values thus obtained for each element are then normalised to iron, under the assumption that a coherent writing phase is characterised by the same ratio of the satellite elements to iron, the main component of the vitriol used to make iron-gall inks in medieval recipes. However, iron is contained in different proportions in the most common writing supports as well. Therefore, for this method to provide reproducible results, the content of iron in the support must show a certain homogeneity and its median value should be considerably lower than the median value of iron intensity detected in the inked areas. This is generally the case of medieval manuscripts written on parchment or European paper. For instance, the simplified version of the fingerprint model could be successfully used in advanced codicological studies on Hamburg, Staats- und Universitätsbibliothek, Cod. germ. 6 (Rabin et al. 2014; Geissbühler et al. 2018). Unfortunately, in the case of ancient papyri, the writing support is hardly ever homogeneous. To begin with, the structure of the plant itself is rather heterogeneous, made of contiguous capillary fibres of 
Fig. 1 Individual values plot for iron. Each dot represents the value of net peak intensity obtained through XRF measurement on a spot of ink or support on two leaves of Rome, Biblioteca Apostolica Vaticana,

Pap. copt. 9. The horizontal dashed line represents the median value per each set of measurements performed using Elio spectrometer

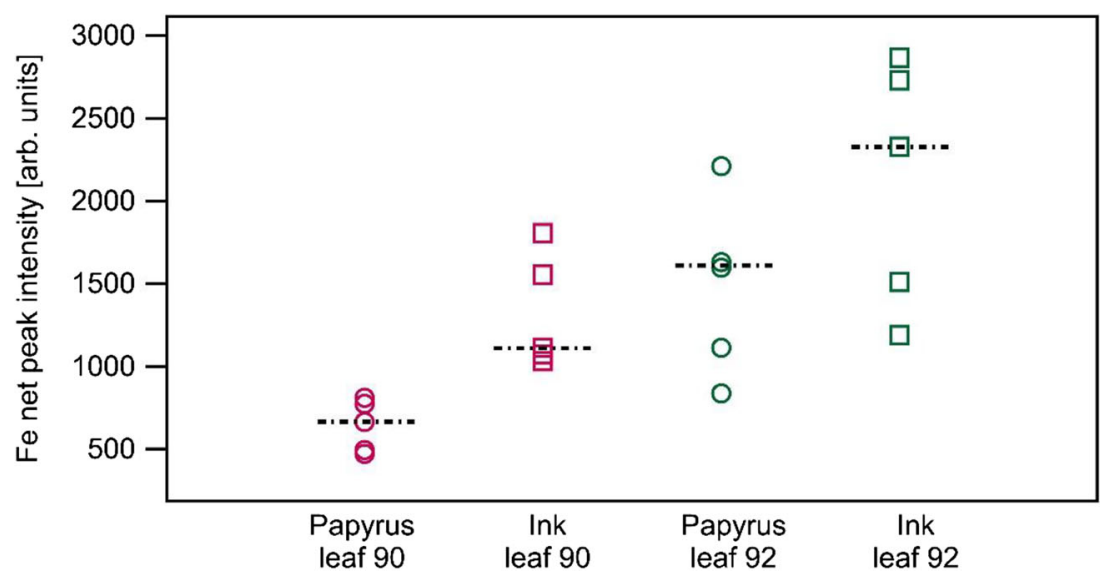

different thickness. Despite the pressure applied during the manufacturing process of the papyrus leaves, the fibrous structure is still recognizable even to the bare eye. In addition, processes of deterioration acting over centuries generally increase the heterogeneity of the leaves, physically affecting each fibre differently. Finally, archaeological material is usually contaminated by different elements depending on the diagenetic surrounding. Unfortunately, iron belongs to the primary pollutant agents, especially in sandy environments. All these processes result in a writing support that is characterised by a widely heterogeneous iron content. Figure 1 shows the distribution of the values for iron measured in the papyrus and in the ink on two different leaves of Apostolic, Vatican Library, Pap. copt. 9. First of all, we see that the iron intensity is far from constant with a larger spread corresponding to the ink. This is not surprising since the thickness of the ink is not necessarily constant throughout the inscribed portions subjected to analysis. Deterioration processes such as flaking or abrasion certainly also contribute to the heterogeneity of the ink thickness. Figure 1 illustrates that exceptional heterogeneity of iron in both papyrus and inks makes quantitative and semiquantitative evaluation rather difficult. Note that the gap between the maximum intensity value in the support and the minimum one in the ink is very small in the case of leaf 90, and non-existent on leaf 92, where the two intervals largely overlap. Under these circumstances, even when it is possible to conduct the XRF measurements for the ink and the support in great proximity, we use the fingerprint model rather cautiously.

However, even in cases in which the semi-quantification of the elements contained in the ink is not possible, we found that the qualitative information collected using our analytical protocol was often enough to discriminate among different clusters of manuscripts when performing a study on a large geographical area and a broad time span. In the following paragraphs, the differences in the elemental composition of the inks examined will be highlighted and discussed.

\section{The literary manuscripts: clusters 1 and 2}

Figure 2 shows the results on Turin, Museo Egizio, Codex IX, classified as cluster 1 . Observing the visible and near-infrared micrograph, we notice a significative change in opacity, indicating that the manuscript investigated had been written with iron-gall ink. Looking at the XRF spectra, we observe that the net peak intensity of the $\mathrm{K} \alpha$ line of iron at $6.4 \mathrm{keV}$ is substantially higher in the inked area as compared with that of the support, confirming this result. The content in potassium may
Fig. 2 Visible and near-infrared micrographs (left top and bottom, respectively) and XRF spectra (right) of an inked and non-inked spot (blue and red, respectively) in Turin, Museo Egizio, Codex IX-Provv. 8592. The XRF measurements were performed using ArtTax spectrometer
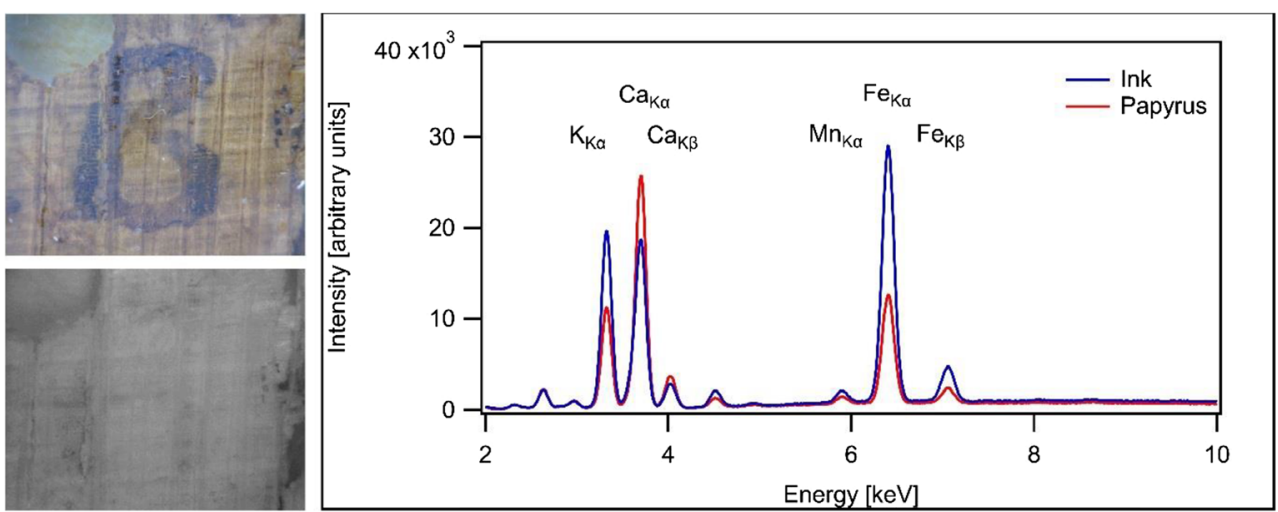
be attributed to the binder and the tannins, while it is surprising that satellite elements like copper and zinc, usually found in vitriol (and largely attested in Medieval European manuscripts and recipes) are absent (Aceto et al. 2017; Geissbühler et al. 2018). During the sixteenth century, the addition of metallic iron to a solution of vitriol became a common procedure to cause the copper to precipitate, leaving a solution rich in iron sulphate (Karpenko and Norris 2002). It seems unlikely that such a technology could have been applied eight centuries before. We believe this might be an indication that common iron filings were used instead of vitriol to prepare this type of iron-gall ink. We have record of the use of this ingredient in Arabic recipes from the Middle Ages onwards. ${ }^{5}$ For this reason, we designate the inks containing only iron as 'non-vitriolic iron-gall inks'. The collection from the library of the Cathedral of Thi(ni)s showed a great homogeneity in the ink composition, given that a similar result was obtained on all the other leaves from cluster 1 , after collecting 30 measurement spots on inks from 6 leaves belonging to 4 different codicological units.

A different type of ink was identified on the leaves of the literary fragments from cluster 2 , originally produced around the fourth century CE, presumably in the area of Panopolis. Figure 3 shows the net intensity profile of the elements iron, potassium, copper and manganese (often associated with iron) extracted from the XRF measurements on Montserrat Abbey, Roca Puig collection, Inv. 145, along the line connecting the papyrus and an inked area, a so-called line scan. We observe that these elements show a similar profile, increasing in intensity when moving from the support to the inked area, attesting that they are all present in the ink. Iron, copper and manganese could be attributed to the metallic salt(s) used to make an irongall ink, while the potassium could be present as a sulphate salt or attributed to the binder or the tannins. However, the interpretation of near-infrared reflectography challenges the possibility that iron-gall ink was indeed used in this case, posing some interesting questions. The ink appears quite pale under near-infrared light, but the comparison between visible and near-infrared micrographs shows only a slight change in opacity, which is in contrast with the one observed on the inks of cluster 1 , or with those we generally observe on medieval iron-gall inks. This makes the typological characterisation of this ink rather uncertain, casting doubts on its nature. Are we looking, instead, at a mixed ink containing both iron-gall ink and carbon? As far as we know, this type of ink was not necessarily produced intentionally. We have records of some Arabic recipes in which the ingredients were roasted, (e.g. Grohmann 1967, p. 129). If this procedure was ever applied to iron-gall inks, carbon would have formed, entering the blend as a by-product. Alternatively, it is plausible that at the

\footnotetext{
${ }^{5}$ Colini C (forthcoming) 'I tried it and it is really good' Replicating recipes of Arabic black inks. Traces of ink: Experiences of Philology and Replication.
}

very beginning of the existence of iron-gall inks, the scarce knowledge regarding their chemical structure resulted in darkish inks rather than black ones, thus carbon may have been used to blacken the mixture. A recent study seems to corroborate this idea, demonstrating that, in contrary to what Robert Fuchs asserts in his definition of 'imperfect inks' (Fuchs 2003), not only gallic acid but also other polyphenols commonly contained in tannins can form darkish complexes with $\mathrm{Fe}^{2+}$, but the complex iron gallate remains the blackest (Díaz Hidalgo et al. 2018). This raises another question: could it be that the ink on Montserrat, Roca Puig, Inv. 145, rather than being a mixed ink, is simply evidence of an undocumented type of ink, prepared using metallic salt(s) and a vegetal ingredient containing mainly other polyphenols than gallic acid? May this be a rough attempt at producing iron-gall ink, obtaining a sort of precursor? In this case, the metalpolyphenol complex(es) formed may be characterised by its own behaviour at $940 \mathrm{~nm}$.

The results obtained on Montserrat, Roca Puig Inv. 145 are coherent within all the 5 leaves examined from the same manuscript and similar to those found on the other codicological units from cluster 2, namely Apostolic Vatican Library, Pap. copt. 9 (Fig. 4) and Montserrat, Roca Puig, Inv. 14. Clearly, the portable equipment we normally employ is not sufficient to fully elucidate the nature of these inks. To unequivocally establish the presence of carbon, the method of choice seems to be IR reflectography performed at longer wavelengths, at which only carbon remains visible. Unfortunately, the dimensions of the equipment partially limit its portability. Another possibility is the application of Raman spectroscopy. However, given the limitation of portable Raman instruments, this analysis often requires bench equipment or the collection of samples. Even in such a case, poor conservation state of the ink often renders the examination fruitless.

Even if possible, the identification of carbon would not provide a complete understanding of the nature of these inks. As discussed, recent experiments proved that the complexity of the inks containing vegetal matter and metallic salts can hardly be described using the term iron-gall ink in a 'traditional' way, i.e. considering only the complex iron-gallic acid as responsible for the ink's properties (Díaz Hidalgo et al. 2018). In addition, the recipes collected in the works of Colini ${ }^{6}$ and Zerdoun show the variety of organic ingredients employed in the manufacturing of the inks (Zerdoun Bat-Yehuda 1983). Against this background, the characterisation of the organic compounds becomes crucial to enable an accurate classification of the typologies of ink. We believe that mass spectrometry performed in atmospheric solid analysis probe (ASAP) mode

\footnotetext{
${ }^{6}$ Colini C (forthcoming) from recipes to material analysis the Arabic tradition of black inks and paper coatings (ninth-twentieth century). Universität Hamburg. Pp: 149-277.
} 
Fig. 3 Visible and near-infrared micrographs (left top and bottom, respectively) and XRF neat peak intensities collected along the line connecting inked and non-inked areas (right) of an ink on Montserrat, Roca Puig collection, Inv. 145. The XRF measurement was performed using ArtTax spectrometer
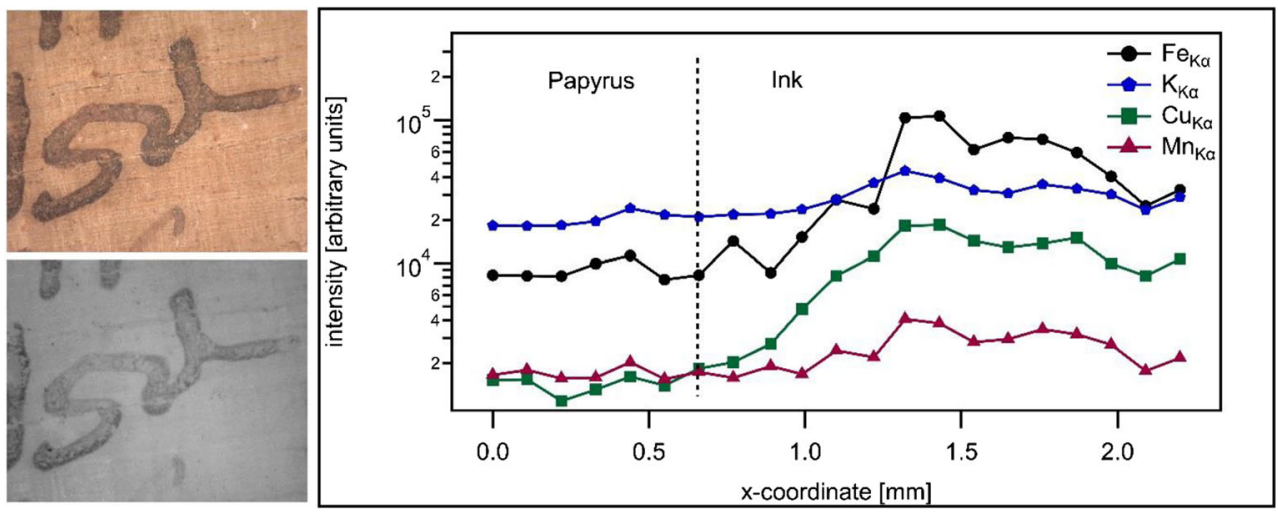

could well serve this purpose. Because of its high sensitivity, this technique may lead to satisfactory and reliable results even on degraded materials and, compared with current mass spectrometry, it has the advantage of being quasi-non-invasive. Including this method in our standard protocol would lead to new insights and a greater level of accuracy in the characterisation of many inks from Late Antiquity that are so far still poorly understood. Some tests on mock samples performed with this technique are presented at the end of this article.

The presence of both copper and iron in the inks attributed to cluster 2 may suggest that vitriol (a mixture of sulphates including iron and copper) was used in their preparation. However, sulphur is a light element; therefore, XRF analysis is sometimes not sensitive enough to detect its presence in the inks examined. Even when it is possible to detect it, it does not deliver an unequivocal proof that its presence must be related to sulphates. Though unlikely, we cannot exclude the possibility that iron and copper entered the ink preparation in a form other than vitriol. In addition, we must consider the possibility that more than one ingredient, each containing different metallic component(s), was employed in the preparation of these inks. The textual examination of the existing recipes does not cast light on this matter, given that the exact composition of many of the ingredients mentioned is still rather unclear, as discussed before. However, although just as a speculation, it is interesting to point out the possible parallel between the inks identified on the manuscripts from cluster 2 and the recipe written in the Papyrus V of Leiden, which dates at the third century $\mathrm{CE}$ and was found in a tomb in Thebes, not far from the area around Panopolis, where the papyri from this cluster may have been produced. The fair amount of copper contained in the inks seems to provide evidence of the use of chalcanthon (a copper-based substance) mentioned in the recipe. If we assume that this compound did not contain any other metallic element besides copper, we could suppose that some iron-based substance may have been added in an attempt to obtain a black complex more suitable for writing. Interestingly, the recipe mentions also misy, a metallic salt of unknown composition that could have provided the content of iron necessary to form the black iron-gallate complex.

\section{The documentary texts: cluster 3}

The results obtained on the documentary texts examined were very different from those obtained on clusters 1 and 2 . Figures 5 and 6 show the near-infrared reflectography performed on inked areas of Montserrat, Roca Puig, Inv. 308 and Inv. 715, respectively. We observe no change in opacity between visible and near-infrared light, thus indicating that both fragments were written using a carbon-based ink. Also, the XRF analysis performed on both documents confirmed
Fig. 4 Visible and near-infrared micrographs (left top and bottom, respectively) and XRF spectra (right) of an inked and non-inked spot (blue and red, respectively) in Rome, Biblioteca Apostolica Vaticana, Pap. copt. 9. The XRF measurements were performed using Elio spectrometer
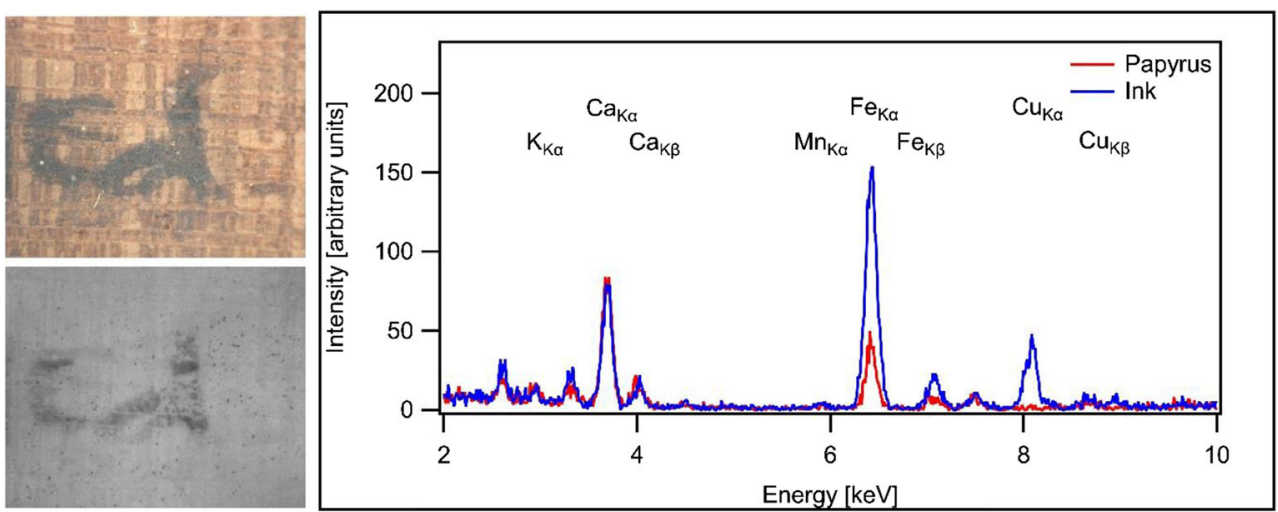
Fig. 5 Montserrat, Roca Puig collection, Inv. 308 (@ Montserrat Abbey). On the right, the micrographs under visible (top) and near-infrared (bottom) light
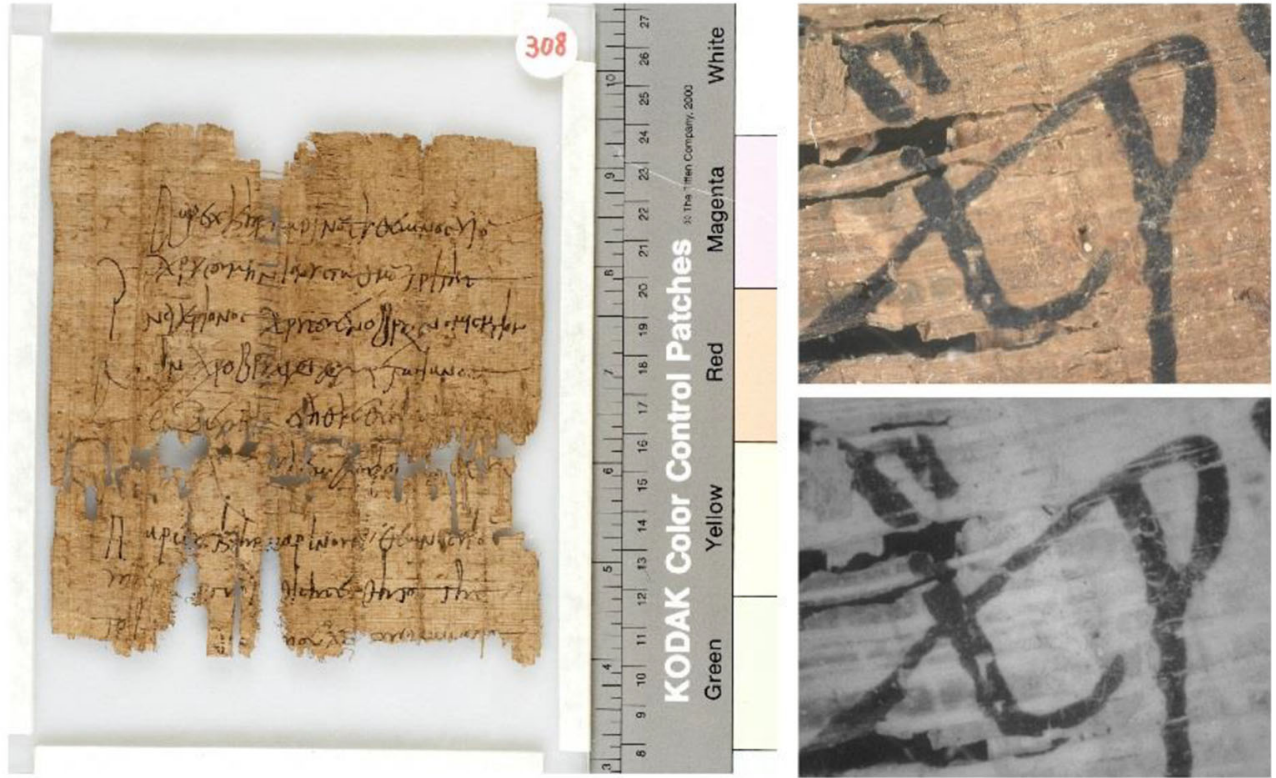

this result since it did not detect any consistent presence of metallic elements.

This is an interesting result considering that these manuscripts are respectively dated at the fifth century $\mathrm{CE}$ and eighth century CE. By this time, iron-gall ink (or at least an ink showing a very different behaviours than carbon under nearinfrared light and containing a fair amount of iron and other metals, maybe a precursor?), was already in use, as demonstrated by the results obtained on the cluster 2 . This poses an interesting question: is it possible that the type of ink used was correlated to the type of manuscript produced, when considering the literary and documentary genres? The results obtained on the full corpus of manuscripts examined so far highlighted the predominant presence of two types of ink that clearly show different features, although an accurate characterisation was not possible due to the limitation of our current analytical protocol. On the one hand, we have a group of inks showing a black colour in the near-infrared region $(940 \mathrm{~nm})$ and no change in opacity when comparing near-infrared and visible images, revealing the presence of a significative amount of carbon black. In some cases, XRF analysis on this group of inks revealed the presence of metals such as iron,
Fig. 6 Montserrat, Roca Puig collection, Inv. 715 (C) Montserrat Abbey). On the right, the micrographs under visible (top) and near-infrared (bottom) light
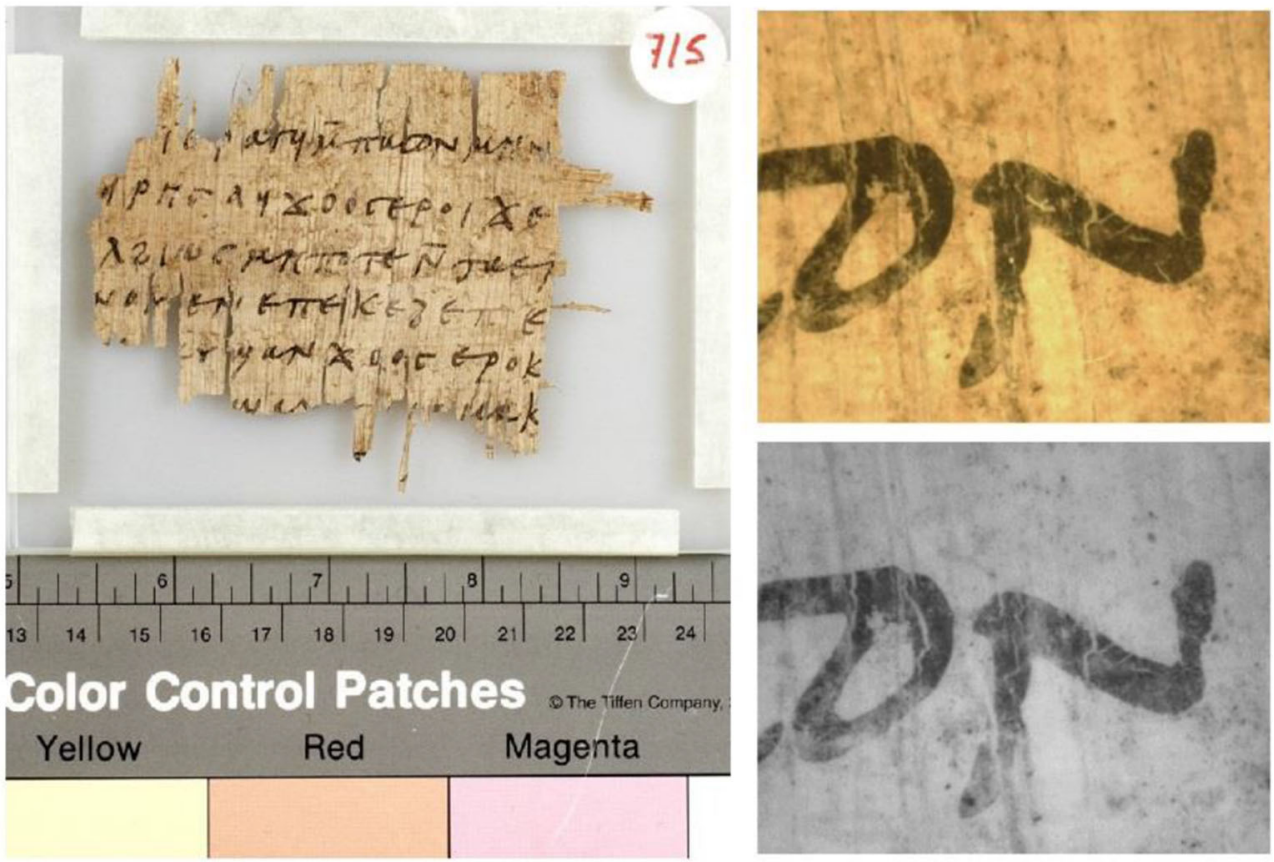
Table 2 Chronological distribution of the manuscripts analysed

\begin{tabular}{|c|c|c|c|c|c|c|}
\hline \multirow[t]{2}{*}{ Century } & \multicolumn{3}{|c|}{ Documentary manuscripts } & \multicolumn{3}{|c|}{ Literary manuscripts } \\
\hline & $\begin{array}{l}\text { Number } \\
\text { of units }\end{array}$ & $\begin{array}{l}\text { Units in carbon- } \\
\text { based ink }\end{array}$ & $\begin{array}{l}\text { Units in } \\
\text { other inks* }\end{array}$ & $\begin{array}{l}\text { Number } \\
\text { of units }\end{array}$ & $\begin{array}{l}\text { Units in iron-gall } \\
\text { ink or similar }\end{array}$ & $\begin{array}{l}\text { Units in } \\
\text { carbon ink }\end{array}$ \\
\hline 2nd & 9 & 9 & - & 3 & - & 3 \\
\hline $3 \mathrm{rd}$ & 2 & 2 & - & - & - & - \\
\hline 4th & 4 & 4 & - & 5 & 5 & - \\
\hline 5 th & 3 & 2 & 1 & 11 & 11 & - \\
\hline 5 th-6th & 1 & 1 & - & 3 & 3 & - \\
\hline 6 th & 6 & 6 & - & 1 & 1 & - \\
\hline 6th-7th & - & - & - & 5 & 5 & - \\
\hline 6th-8th & 1 & 1 & - & - & - & - \\
\hline 7 th & 5 & 5 & - & 1 & 1 & - \\
\hline 7th-8th & 6 & 5 & 1 & 4 & 4 & - \\
\hline 8 th & 33 & 25 & 8 & 1 & 1 & - \\
\hline Total & 70 & 60 & 10 & 34 & 31 & 3 \\
\hline
\end{tabular}

*Here, 'Other inks' include iron-gall ink, mixed ink and coloured inks copper and in some rare cases, lead. On the other hand, we have inks showing a pale colour in the near-infrared region $(940 \mathrm{~nm})$, at least a slight change in opacity when comparing visible and near-infrared micrographs and containing a significant and consistent amount of metals. In some cases, they are clearly identified as iron-gall inks, while in others, the characterisation is more problematic, but given the consistent presence of iron and other metals, they may be defined as 'similar to iron-gall ink'. These inks occasionally presented signs of corrosion. It is very interesting to discuss the distribution of these two groups of inks along the corpus. Carbon-based ink has been found on 60 out of 70 documentary texts, representing more than $80 \%$ of cases in a time span between second and eighth centuries CE. For the sake of clarity, Table 2 shows the chronological distribution of the units analysed, along with the typology of ink found on their leaves. In contrast, iron-gall ink or similar has been found on 31 out of 34 literary texts, representing more than the $90 \%$ of cases in the same time span. The use of this type of ink in literary manuscripts continues between the ninth and eleventh centuries $\mathrm{CE}$, when it was found on all the 30 units analysed. Similarly, it was found on all the 13 literary manuscripts from the Michaelides collection ${ }^{7}$ that were analysed at the Cambridge University Library. Although this collection has been poorly studied and a date for every single manuscript has still not been established, its leaves can be placed in a time span between the sixth and tenth centuries CE.

\footnotetext{
${ }^{7}$ This collection includes papyrus, parchment and paper fragments and originally belonged to the Greek collector George Michaelides. We have no secure information on the provenance of these manuscripts. In an article from 1952, Michaelides vaguely refers to a native from Egypt bringing him Coptic and Greek manuscripts from Fayuum (Michailides 1952, p. 45).
}

The results obtained suggest that the transition between carbon ink, used everywhere in antiquity, and iron-gall ink, very popular in Medieval Europe, did not happen as a result of the mere function of time. Other factors, like the environment of production of a manuscript (given that documentary and literary texts were most likely produced in different environments), influenced the type of ink used. No other correlation of this dimension was observed between type of ink and support, as it was previously suggested (Lucas 1922; Macarthur 1995), neither was it found between ink and language, as demonstrated in Table 3, where the results obtained are sorted according to the language of each unit examined.

The choice of certain materials for the manufacturing of manuscripts must have been the result of economic factors. Poorer environments of production probably used cheaper ingredients to prepare the inks. It is possible that less expensive ingredients were mixed together with more pricey ones to function as diluents, and this may have conducted to the production of mixed inks. Unfortunately, to date we have no records stating the cost of one or another type of ink, nor of its ingredients. It may seem logical to think that carbon ink has always been cheaper, given that charcoal or soot can be easily produced by combustion of a variety of common materials, such as pine logs as described by Pliny. However, Pliny mentions also the soot obtained from the combustion of ivory (precious and therefore more expensive) and the importation of carbon ink from India, suggesting that different qualities of carbon ink were circulating at that time, given that these last ones must have been finer and more expensive. At this point, it is difficult to say whether iron-gall ink was higher-priced than ivory soot or Indian carbon ink, making it impossible to draw any conclusion on this matter until further analytical and historical information is made available. On top of the 
Table 3 Distribution of the languages in the documentary manuscripts between the second and eighth centuries $\mathrm{CE}$. The bilingual units appear twice in the table

\begin{tabular}{llllllll}
\hline Language & \multicolumn{2}{l}{ Documentary manuscripts } & & & \multicolumn{2}{l}{ Literary manuscripts } \\
\cline { 2 - 3 } & $\begin{array}{l}\text { Number of } \\
\text { units }\end{array}$ & $\begin{array}{l}\text { Units in } \\
\text { carbon ink }\end{array}$ & $\begin{array}{l}\text { Units in other } \\
\text { inks* }\end{array}$ & & $\begin{array}{l}\text { Number of } \\
\text { units }\end{array}$ & $\begin{array}{l}\text { Units in iron- } \\
\text { gall ink }\end{array}$ & $\begin{array}{l}\text { Units in } \\
\text { carbon ink }\end{array}$ \\
\hline Coptic & 43 & 35 & 8 & 23 & 23 & - \\
Greek & 27 & 25 & 2 & 11 & 8 & 3 \\
Latin & 1 & 1 & - & 1 & 1 & - \\
Total & 70 & 60 & 10 & 34 & 31 & 3 \\
\hline
\end{tabular}

*Here, 'Other inks' include iron-gall ink, mixed ink and coloured inks economic factors, there is a possibility that the choice behind the type of ink used was linked to the physical properties of carbon and iron-gall ink. The former simply sits on top of the support, adhering to it thanks to the binder, but it can be easily scraped off, even accidentally, and it is therefore more suitable in the case of ephemeral manuscripts, as in the case of receipts or private messages. In this regard, we have record of an epigraph by Martial dating from the first century CE who describes the process of removal of an ink using a 'Punic sponge'. This proves that the practice of erasing an ink from the support once the text has lost its relevance was in use at that time (Martial 2015, pp. 67-69). In contrast, iron-gall ink penetrates the support deeply and it can be erased only in critical acidic conditions that can be achieved, for instance, by intentionally treating the ink with weak acids. Its durability makes this type of ink the best choice when writing a manuscript with the specific intention to make it last in time, as it is the case with literary texts, especially of literary codices produced as part of the library of a religious institution (it must be stressed that these represent most cases existing in the corpus examined). The manuscripts from the library of the Cathedral of Thi(ni)is, presented in this work as the cluster of manuscripts number 1, may well serve as an example. Clearly, the scenario described so far is only a partial interpretation of a much more complex phenomenon that still requires further investigation, especially focusing on those documentary texts that may have been produced with the intention to last in time, such as testaments. As a final remark, it must be stressed that the data collected so far is representative mainly of the areas of Bawit, Oxyrhynchus, Thi(ni)s and the area around Panopolis. There is a big portion of Egyptian geography that could not so far be covered, despite the logistical efforts. In addition, until now, it was not possible to compare directly a significative number of literary and documentary texts coming from the same area and dating to the same time. Therefore, the results presented in this work provide far from a homogeneous representation of the whole Egyptian reality in the time span considered. We must acknowledge that the general situation may have been very different from the one represented by the analytical data collected.

\section{Tests with ASAP Xevo G2-XS QTOF waters}

Given the difficulties previously described in characterising the inks of some of the manuscript in our corpus, the goal of this experiment was to prove the effectiveness of the method in the identification of organic compounds, this time centring our attention on hydrolysable tannins. These can be found in high amounts in gallnuts. The latter have been already studied using mass spectrometry in conjunction with chromatography (Arpino et al. 1977; Mämmelä et al. 2000). The main purpose of those studies was the identification of different tannins or tannin mixtures rather than the mere verification of their presence. We propose to use gallic acid and ellagic acid, with molar masses of 170.12 and 302.2 respectively, that can be found in high amounts in gallnuts, as well as pyrogallol (molar mass 126.11) detected as a daughter ion of gallic acid in the mass spectra obtained with different ionisation techniques (Wyrepkowski et al. 2014), as indicators of the presence of tannins in the mixture. Previous studies on the tanned parchment of Dead Sea Scrolls proved that it was possible to identify at least gallic acid even on heavily deteriorated materials (Reed and Poole 1964). For the purpose
Table 4 Description of the samples analysed and their results

\begin{tabular}{lllll}
\hline Sample & Description & Pyrogallol & Gallic acid & Ellagic acid \\
\hline A & Gallnut extract & $\sqrt{ }$ & $\sqrt{ }$ & $\sqrt{ }$ \\
B & Iron-gall ink prepared mixing gallnut extract and & $\sqrt{ }$ & $\sqrt{ }$ & $\sqrt{ }$ \\
& $\quad$ iron sulphate & & $\sqrt{ }$ & - \\
C & Mixed ink obtained mixing iron gall as in B and carbon & $\sqrt{ }$ & $\sqrt{ }$ \\
D & Copper ink prepared mixing gallnut extract & $\sqrt{ }$ & $\sqrt{ }$ & $\sqrt{ }$ \\
& $\quad$ and copper sulphate & & & \\
\hline
\end{tabular}


Fig. 7 Mass spectrum of the sample B. The ions of pyrogallol, gallic and ellagic acid are found respectively at $125.02,169.01$ and $301.00 \mathrm{~m} / \mathrm{z}$. The signal at $126.90 \mathrm{~m} / \mathrm{z}$ is due to calibration of the machine using iodide ion
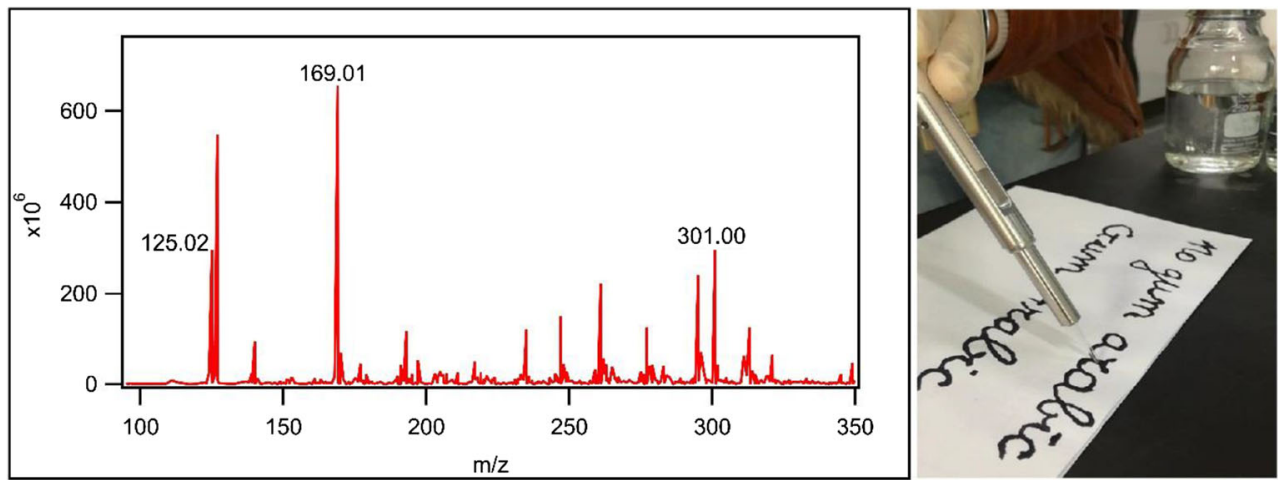

of this study, four mock samples of different typologies of ink were prepared using gallnut extract and analysed both liquid and dry, to make sure that their physical state would not influence the final result. The microsampling was performed by either rubbing a glass wire onto the dry sample or immersing it into the liquid. In both cases, the amount of sample collected was invisible to the naked eye. No further sample preparation was needed; the glass holder was inserted directly in the machine for examination. Since the analysis was performed using negative-ion pattern, the precursor ions of pyrogallol, gallic and ellagic acid are found respectively at around 125, 169 and $301 \mathrm{~m} / \mathrm{z}$. Table 4 lists the description of the samples and the results obtained.

We find it encouraging that all the samples investigated showed prominent peaks corresponding to at least two out of three characteristic components of the family of hydrolysable tannins and consider it to be a demonstration of the effectiveness of the technique in the identification of these components. In this preliminary study, we neither studied the effects of the ionisation conditions on the resulting spectra nor used a collision cell for controlling the fragmentation processes. Despite this fact, gallic acid and its fragment pyrogallol seem to be easily detectable whereas a lower amount of ellagic acid might pose a problem. Figure 7 shows the sampling technique as well as the mass spectrum of sample B, on which the peaks corresponding to deprotonated pyrogallol, gallic acid and ellagic acid have been highlighted.

\section{Conclusion}

The first results of this study show that the use of a rather simple analytical protocol leading to only partial characterisation of inks used in Egypt during Late Antiquity could be sufficient to cluster the inks according to their types. This observation suggests that such a typological diversity in the composition of the inks can be potentially exploited to collocate an unknown manuscript in space and time, once a proper geochronological map based on a statistically relevant amount of data is assembled. However, to refine the classification of the inks, other techniques for a routine identification of organic components must be added to our protocol. The present study indicates that ASAP-MS might be the technique of our choice, because of its high sensitivity coupled with a quasi-non-invasive and versatile sampling method.

Acknowledgements We would like to acknowledge the help of the library personnel who permitted us to access the manuscripts and supported every step of our analytical campaigns. Our special thanks go to the staff of the Museo Egizio in Turin, especially to Susanne Töpfer and Sara Aicardi. Warm thanks are also due to the staff of the collection Roca Puig in Montserrat and Palau Ribes in Barcelona, in particular to Sofía Torallas Tovar, Alberto Nodar Dominguez and Maria Jesús Albarrán Martinez. Special thanks as well to Paolo Vian, Delio Vania Proverbio, Irma Schuler, Angela Nuñez and the staff of the conservation laboratory at the Biblioteca Apotolica Vaticana. We are very thankful to Dr. Winkler from Waters Gmbh for the help and support received in performing the ASAP-MS analysis. Finally, we are deeply indebted to our colleagues in the Bundesanstalt fur Materialforschung und -prüfung, especially, Oliver Hahn, Olivier Bonnerot, Simon Steger and Zina Cohen.

Authors' contributions Tea Ghigo performed the analytical campaigns, evaluated the data collected and prepared the manuscript. Ira Rabin provided feedback during the data evaluation and revised the manuscript. Paola Buzi revised the historical and codicological part of the manuscript.

Funding information Open Access funding provided by Projekt DEAL. The research presented in this article has been funded by the European Research Council, Horizon 2020 Programme, with an ERC Advanced Grant 2015 destined to support the project 'Tracking Papyrus and Parchment Paths: An Archaeological Atlas of Coptic Literature. Literary Texts in their Geographical Context: Production, Copying, Usage, Dissemination and Storage', project no. 687567, P.I. Paola Buzi [http://paths.uniroma1.it/]. The archaeometric analysis was supported by the Cluster of Excellence 'Understanding Written Artefacts' funded by the German Research Foundation (Deutsche Forschungsgemeinschaft, DFG), and within the scope of the Centre for the Study of Manuscript Cultures (CSMC) at the University of Hamburg.

Open Access This article is licensed under a Creative Commons Attribution 4.0 International License, which permits use, sharing, adaptation, distribution and reproduction in any medium or format, as long as you give appropriate credit to the original author(s) and the source, provide a link to the Creative Commons licence, and indicate if changes were made. The images or other third party material in this article are included in the article's Creative Commons licence, unless indicated otherwise in a credit line to the material. If material is not included in the article's Creative Commons licence and your intended use is not permitted by statutory regulation or exceeds the permitted use, you will need to obtain 
permission directly from the copyright holder. To view a copy of this licence, visit http://creativecommons.org/licenses/by/4.0/.

\section{References}

Aceto M, Agostino A, Boccaleri E, Garlanda AC (2008) The Vercelli Gospels laid open: an investigation into the inks used to write the oldest Gospels in Latin. X-Ray Spectrom 37:286-292

Aceto M, Agostino A, Fenoglio G, Baraldi P, Zannini P, Hofmann C, Gamillscheg E (2012) First analytical evidences of precious colourants on Mediterranean illuminated manuscripts. Spectrochim Acta A Mol Biomol Spectrosc 95:235-245

Aceto M, Agostino A, Fenoglio G, Capra V, Demaria E, Cancian P (2017) Characterisation of the different hands in the composition of a 14th century breviary by means of portable XRF analysis and complementary techniques. X-Ray Spectrom 46:259-270

Aceto M, Calà E (2017) Analytical evidences of the use of iron-gall ink as a pigment on miniature paintings. Spectrochim Acta A Mol Biomol Spectrosc 187:1-8

Arpino P, Moreau J-P, Oruezabal C, Flieder F (1977) Gas chromatographic-mass spectrometric analysis of tannin hydrolysates from the ink of ancient manuscripts (XIth to XVIth century). J Chromatogr A 134:433-439

Bailey K (1932) Elder Pliny's chapters on chemical subjects: Part II. Arnold, London

Bausi A (2018) Translations in Late Antique Ethiopia. In: Egitto crocevia di traduzioni. EUT Edizioni Università di Trieste, Trieste, pp 69-99

Bicchieri M, Monti M, Piantanida G, Sodo A (2013) Non-destructive spectroscopic investigation on historic Yemenite scriptorial fragments: evidence of different degradation and recipes for iron tannic inks. Anal Bioanal Chem 405:2713-2721

Brun E, Cotte M, Wright J, Ruat M, Tack P, Vincze L, Ferrero C, Delattre D, Mocella V (2016) Revealing metallic ink in Herculaneum papyri. Proc Natl Acad Sci 113:3751-3754

Buzi P (2017) Tracking papyrus and parchment paths: an archaeological atlas of Coptic literature; literary texts in their geographical context; production, copying, usage, dissemination and storage (PAThs). Early Christ 8:507-516

Buzi P (2018a) Egypt, crossroad of translations and literary interweavings (3rd-6th centuries). A reconsideration of earlier Coptic literature. In: Egitto crocevia di traduzioni. EUT Edizioni Università di Trieste, Trieste, pp 15-67

Buzi P (2018b) The Coptic Papyrus Codices preserved in the Museo Egizio, Turin: new historical acquisitions, analysis of codicological features, and strategies for a better understanding and valorization of the library from Thi(ni)s. Adamantius 24:39-57

Christiansen T, Cotte M, Loredo-Portales R, Lindelof PE, Mortensen K, Ryholt K, Larsen S (2017) The nature of ancient Egyptian coppercontaining carbon inks is revealed by synchrotron radiation based X-ray microscopy. Sci Rep 7:1-8. https://doi.org/10.1038/s41598$017-15652-7$

Colini C, Hahn O, Bonnerot O, Steger S, Cohen Z, Ghigo T, Christiansen T, Bicchieri M, Biocca P, Krutzsch M, Rabin I (2018) The quest for the mixed inks. In: MC, vol 11, pp 41-49

Delange E, Grange M, Kusko B, Menei E (1990) Apparition de l'encre métallogallique en Egypte à partir de la collection de papyrus du Louvre. Rev Egyptologie 41:213-217

Díaz Hidalgo RJ, Córdoba R, Nabais P, Silva V, Melo MJ, Pina F, Teixeira N, Freitas V (2018) New insights into iron-gall inks through the use of historically accurate reconstructions. Herit Sci 6:1-15. https://doi.org/10.1186/s40494-018-0228-8

Dioscorides Pedanius, Osbaldeston TA, Wood RP (2000) De materia medica. Being an herbal with many other medicinal materials, written in Greek in the first century of the common era: a new indexed version in modern English. IBIDIS, Johannesburg

Fournet J-L (2015) Anatomie d'une bibliothèque de l'Antiquité tardive: l'inventaire, le faciès et la provenance de la'Bibliothèque Bodmer'. Adamantius 21:8-37

Fuchs R (2003) The history of chemical reinforcement of texts in manuscript-what should we do now. In: Care and Conservation of Manuscripts 7, Proceedings of the Seventh International Seminar Held at the Royal Library. Museum Tusculanum Press Copenhagen, Denmark, pp 159-170

Garlan Y (1974) Recherches de poliorcétique grecque, Bibliothèque des Écoles Françaises d'Athènes et de Rome. Diffusion de Boccard, Paris

Geissbühler M, Dietz G, Hahn O, Rabin I (2018) Advanced codicological studies of Cod. germ. 6 (Hamburg, Staats-und Universitätsbibliothek): Part 2. MC 11:133-139

Ghigo T, Bonnerot O, Buzi P, Krutzsch M, Hahn O, Rabin I (2018) An attempt at a systematic study of inks from Coptic Manuscripts. MC $11: 157-164$

Grohmann A (1967) Arabische Paläographie: I. Teil. Hermann Böhaus, Wien

Hahn O, Heiles M, Rabin I (2018) Palaeography and X-ray fluorescence spectroscopy: manuscript production and censorship of the fifteenth century German Manuscript, State and University Library Hamburg, Cod. germ. 1. MC 11:109-132

Hahn O, Malzer W, Kanngießer B, Beckhoff B (2004) Characterization of iron-gall inks in historical manuscripts and music compositions using x-ray fluorescence spectrometry. X-Ray Spectrom 33:234 239

Hahn O, Wolff T, Feistel H-O, Rabin I, Beit-Arié M (2007) The Erfurt Hebrew Giant Bible and the experimental XRF analysis of ink and plummet composition. Gaz Livre Médiév 51:16-29

Karpenko V, Norris JA (2002) Vitriol in the history of chemistry. Chem List 96:997-1005

Kolar J, Strlic M (2006) Iron gall inks: on manufacture, characterisation, degradation and stabilisation. National and University Library of Slovenia, Ljubljana

Lucas A (1922) The inks of ancient and modern Egypt. Analyst 47:9-15

Lundhaug H, Jenott L (2015) The monastic origins of the Nag Hammadi codices. Mohr Siebeck, Tübingen

Macarthur D (1995) AGLAE et l'étude des encres et des colorants de manuscrits. Techne 2:68-75

Mämmelä P, Savolainen H, Lindroos L, Kangas J, Vartiainen T (2000) Analysis of oak tannins by liquid chromatography-electrospray ionisation mass spectrometry. J Chromatogr A 891:75-83

Martial (2015) Epigrams: with parallel Latin text. OUP, Oxford

Michailides G (1952) Papyrus contenant un dessin du dieu Seth à tête d'âne. Aegyptus 32:45-53

Mrusek R, Fuchs R, Oltrogge D (1995) Spektrale Fenster zur Vergangenheit Ein neues Reflektographieverfahren zur Untersuchung von Buchmalerei und historischem Schriftgut. Naturwissenschaften 82:68-79

Nicholson PT, Shaw I (2000) Ancient Egyptian materials and technology. CUP, Cambridge

Nir-El Y, Broshi M (1996) The black ink of the Qumran scrolls. Dead Sea Discov 3:157-167

Preisendanz K (1931) Papyri Graecae magicae. Die Griechischen Zauberpapyri, herausgegeben und übersetzt von Karl Preisendanz, V. 2. Teubner, Berlin

Rabin I (2017) Building a bridge from the Dead Sea scrolls to mediaeval Hebrew Manuscripts. In: Jewish manuscript cultures new perspectives. De Gruyter, Berlin, pp 310-322

Rabin I, Hahn O, Geissbühler M (2014) Combining codicology and Xray spectrometry to unveil the history of production of codex germanicus 6 (Staats-und Universitätsbibliothek Hamburg). MC 7: 126-131 
Rabin I, Schütz R, Kohl A, Wolff T, Tagle R, Pentzien S, Hahn O, Emmel $S$ (2012) Identification and classification of historical writing inks in spectroscopy: a methodological overview. Comp Orient Manuscr Stud COMSt Newsl 3:26-30

Reed R, Poole JB (1964) A study of some Dead Sea Scroll and leather fragments from Cave 4 at Qumran. Part II-Chemical Examination. In: Proceedings of the Leeds Philosophical and Literary Society: Scientific Section, pp 171-182

Rouchon V, Bernard S (2015) Mapping iron gall ink penetration within paper fibres using scanning transmission X-ray microscopy. J Anal At Spectrom 30:635-641

Rouchon-Quillet V, Remazeilles C, Bernard J, Wattiaux A, Fournes L (2004) The impact of gallic acid on iron gall ink corrosion. Appl Phys A Mater Sci Process 79:389-392

Schubert P (2015) Les papyrus Bodmer: contribution à une tentative de délimitation. Adamantius 21:41-46
Theophilus P (1979) De diversis artibus. Dover Publications, New York, English

Torallas Tovar S (2018) Athanasius' Letter to Dracontius: a FourthCentury Coptic Translation in a Papyrus Roll (P. Monts. Roca inv. 14). Adamantius 24:22-38

Wyrepkowski C, Gomes da Costa D, Sinhorin A, Vilegas W, De Grandis R, Resende F, Varanda E, dos Santos L (2014) Characterization and quantification of the compounds of the ethanolic extract from Caesalpinia ferrea stem bark and evaluation of their mutagenic activity. Molecules 19:16039-16057

Zerdoun Bat-Yehuda M (1983) Les Encres noires au Moyen-Âge (jusqu'à 1600). Éditions du Centre National de la Recherche Scientifique, Paris

Publisher's note Springer Nature remains neutral with regard to jurisdictional claims in published maps and institutional affiliations. 